International Journal of Business Management and Economic Review

Vol. 3, No. 06; 2020

ISSN: 2581-4664

\title{
SUSTAINABILITY THOUGHTS 118: HOW CAN THE GREEN COLD WAR, THE 2012 RIO +20 CONFERENCE ACTIONS, AND THE FALL OF PERFECT ENVIRONMENTALISM BE LINKED? WHAT ARE THE IMPLICATIONS OF THIS IN TERMS OF WINNERS AND LOSERS AND OF ENVIRONMENTAL SUSTAINABILITY?
}

\author{
Lucio Muñoz* \\ Independent qualitative comparative researcher/consultant, Vancouver, BC, Canada
}

http://doi.org/10.35409/IJBMER.2020.3215

\begin{abstract}
The idea of win-win economy-environment coalitions as the solution to the green cold war that started to gain relevance in the 1960s came forward; and it was widely accepted by governments and international institutions after the Brundtland Commission called in 1987 for the need to address the environmental issue, setting the stage for the Rio conference process to begin in 1992 with the first earth summit, and which culminated in the 2012 Rio +20 conference where this green cold war was supposed to be scientifically settled. There were two solutions to the green cold war in 2012, a science based solution; and an arbitrary solution. As science was at the heart of the 2012 Rio +20 conference before and during the conference, then a shift towards green market thinking, green economy thinking and green growth thinking was the expected solution as it is the only science based solution possible according to paradigm death and shift expectations so as to preserve the core principle or core values of the two merging paradigms, the economy and the environment; and hence for the conference to say in 2012 they were going the green market way was not a surprise. At the heart of green markets is perfect environmentalism as environmental sustainability is a necessary condition for green markets to exist. That means that going the way of environmental externality management markets in practice after Rio +20 instead of green markets when they said they were going green markets was and is an arbitrary decision, not a science based decision since at the heart of those markets is imperfect environmentalism and imperfect market thinking; and hence those markets do no require environmental sustainability to exist. In other words, the flipping of options to solve the green cold war then from perfect markets to environmental externality management markets has important implications both in terms of winner and losers in particular; and in terms of environmental sustainability in general, yet those implications are little understood as nothing as far as I know has been written about this from the sustainability angle. The discussion above raises questions such as how can the green cold war, the 2012 Rio +20 conference actions, and the fall of perfect environmentalism be linked? What are the implications of this in terms of winners and losers and of environmental sustainability? The main goal of this paper is to provide an answer to these questions using qualitative comparative means.
\end{abstract}


Vol. 3, No. 06; 2020

ISSN: 2581-4664

Keyword: Sustainability, traditional market, environmental market, green market, environmental externality management market, green cold war, sustainability gaps, economic sustainability gap, environmental sustainability gap, paradigm shift, paradigm death, paradigm merger.

\section{INTRODUCTION}

The idea of win-win economy-environment coalitions as the solution to the green cold war that started to gain relevance in the 1960s(Carson 1962; Mackie 2017) came forward and it was widely accepted by governments and international institutions after the Brundtland Commission(WCED 1987) called in 1987 for the need to address the environmental issue, setting the stage for the Rio conference process to begin in 1992 with the first earth summit(UN 1992), and which culminated in the 2012 Rio + 20 conference(UNCSD 2012a; UNCSD 2012b) where this green cold war was supposed to be scientifically settled. The structure of the green cold war in terms of sustainability gaps was recently highlighted(Muñoz 2020 ) as indicated in Figure 1 below:

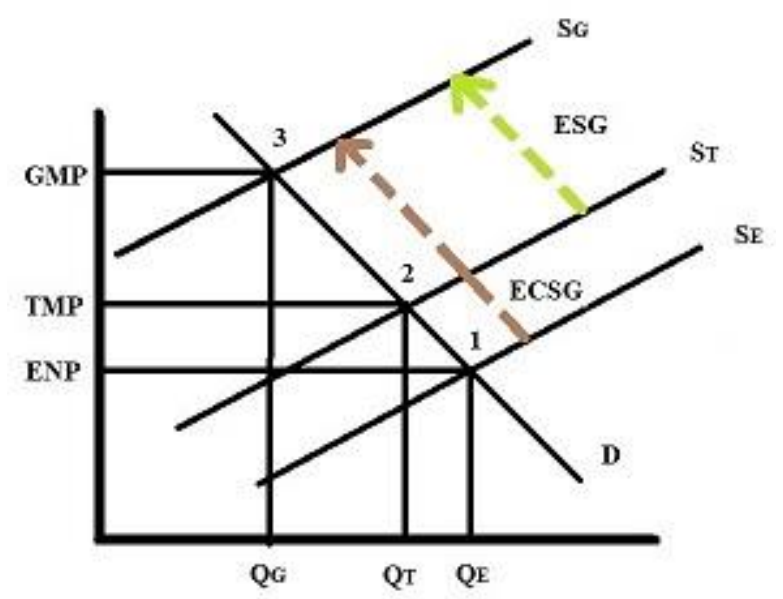

Figure 1 The green cold war in terms of sustainability gaps

Figure 1 above tells us that the green cold war simply is a clash between the economic sustainability gap(ECSG) affecting the environmental market(ENM) as indicated by broken arrow going from point 1 to point 3 and the environmental sustainability gap(ESG) affecting the traditional market(TM) as indicated by the broken arrow going from point 2 to point 3 .

b) The options the 2012 Rio +20 had to solve the green cold war

There were two solutions to the green cold war in 2012, a science based solution; and an arbitrary solution, which are addressed below in detail:

i) A science based option

As science was at the heart of the 2012 Rio +20 conference before and during the conference, then a shift towards green market thinking, green economy thinking and green growth thinking was the expected solution as it is the only science based solution possible according to paradigm death and shift expectations(Muñoz 2019) so as to preserve the core principle or core values of the two merging paradigms, the economy and the environment; and hence for the conference to say they were going the green market way was not a surprise. At the 


\section{International Journal of Business Management and Economic Review}

Vol. 3, No. 06; 2020

ISSN: 2581-4664

heart of green markets is perfect environmentalism as environmental sustainability is a necessary condition for green markets to exist. If Rio +20 conference had followed the science based option to resolve the green cold war through the fixing of the traditional market, then the only thing they had to do was to fully close the environmental sustainability gap(ESG) between point 3 and point 2 in Figure 1 above to shift the traditional market structure to the green market structure $(\mathrm{TM}=\mathrm{Bc}--\rightarrow \mathrm{BC}=\mathrm{GM})$. The closing of the environmental sustainability gaps shifts the perfect traditional market(TM) towards the perfect green market(GM)(Muñoz 2016a). The green market structure graphically is found at point 3 in Figure 1 above, which can be stated analytically as indicated below:

1) $\mathbf{G M}=\mathbf{B C}$

Expression 1) simply says that the necessary and sufficient condition for green markets(GM) to exist is the presence of economic sustainability(B) and environmental sustainability $(\mathrm{C})$ at the same time as it is a win-win coalition between the perfect economic thinking and the perfect environmental thinking. And hence, green markets are a two component based sustainability model with no environmental sustainability gaps. The structure of green markets(GM) can be appreciated better in Figure 2 below:

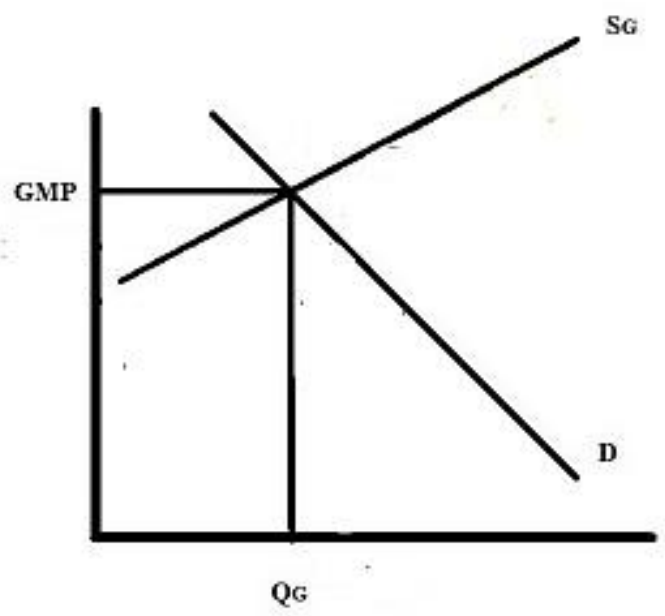

Figure 2 The structure of the green market(GM)

The market is cleared by the green market

price(GMP)

We can see in Figure 2 above that the interaction of the green supply $\mathrm{S}_{\mathrm{G}}$ and demand(D) determine the green market price $(\mathrm{GMP}=\mathrm{GP})$ and the green quantity $\left(\mathrm{Q}_{\mathrm{G}}\right)$ to be produced and consumed as they are free markets, where government intervention is possible, but only in cases of green market failure.

Therefore, the green market structure shown in Figure 2 above is the perfect win-win model as it is a full win economy-full win environment model, where the economic agents are environmentally responsible and the environmental agents are financially responsible; and since Rio +20 was looking for perfect win-win solutions then going green markets was the expected choice.

\section{ii) An arbitrary option}

That means that going the way of environmental externality management markets in 


\section{International Journal of Business Management and Economic Review}

Vol. 3, No. 06; 2020

ISSN: 2581-4664

practice after Rio +20 instead of going green markets when they said they were going green markets was and is an arbitrary decision, not a science based decision as at the heart of those markets is imperfect environmentalism; and hence those markets do not require environmental sustainability to exist. Since Rio +20 conference in practice followed the non-science based option to resolve the green cold war through the patching of the traditional market, then the only thing they had to do to prevent the paradigm shift to green markets(GM) and implement the paradigm patching was to place an externality management supply $\mathrm{S}_{\mathrm{EEM}}$ below green market supply $S_{G}$ and above the traditional market supply $S_{T}$ in Figure 1 above since any market between point 3 and point 2 is an externality management market, and when the externality management supply $\mathrm{S}_{\mathrm{EEM}}$ cuts the environmental sustainability gap(ESG) associated with the traditional market(TM) it becomes an environmental externality management market(EEMM), and its structure can be stated analytically as follows:

2) $\mathbf{E E M M}=\mathbf{B C}_{M}$

Expression 2) simply tell us that the necessary and sufficient condition for environmental externality management markets(EEMM) to exist is the presence of economic sustainability(B) and environmental externality management $\left(\mathrm{C}_{\mathrm{M}}\right)$ at the same time as it is a win-win coalition between the imperfect economic thinking and the imperfect environmental thinking. Notice that here environmental sustainability it is not a requirement for environmental externality management markets to exist, but environmental externality management is. And hence, environmental externality management markets(EEMM) are a one component based sustainability model still with environmental sustainability gaps. The going the non-green market way has been highlighted as starting with the wrong green foot when addressing environmental sustainability issues(Muñoz 2016b). The structure of the environmental externality management market(EEMM) can be appreciated better in Figure 3 below:

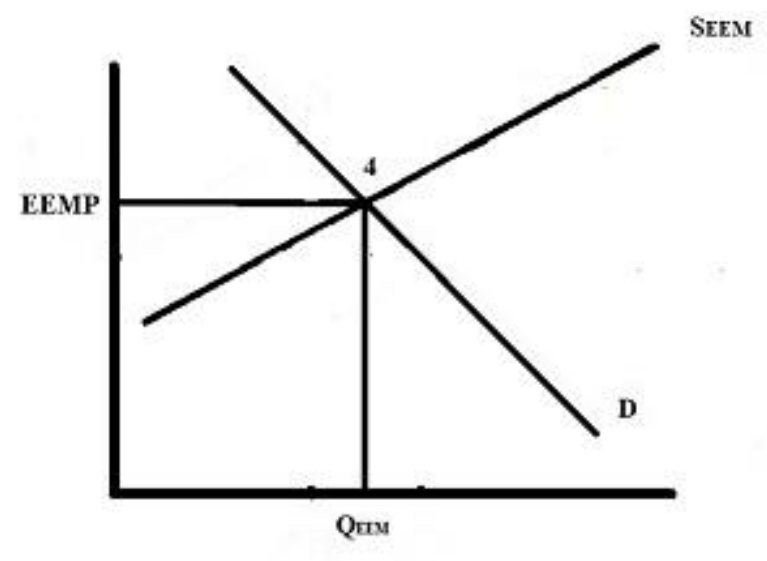

Figure 3 The structure of the environmental externality management market(EEMM)

It is cleared by the environmental externality

management market price(EEMP).

We can see in Figure 3 above that the environmental externality management price(EEMP) determines the quantity to be produced and consumed(QEEM) as here demand and supply interactions do not determine the market price as environmental externality management costs are set externally because environmental externality management markets(EEMM) are not free 


\section{International Journal of Business Management and Economic Review}

Vol. 3, No. 06; 2020

ISSN: 2581-4664

markets.

Hence, the EEMM market depicted in Figure 3 above is an imperfect win-win model as it is a full win economy-partial win environment model, where the economic agents do not have to be fully environmentally responsible and the environmental agents do not have to be fully financially responsible; and since Rio +20 was looking for perfect win-win solutions, then going environmental externality management(EEMM) was not the expected choice, but an arbitrary choice.

\section{c) Linking the structure of the science based option and of the arbitrary option}

Placing the green market(GM) and the environmental externality management market(EEMM) in conflict conditions helps us uncover the existence of a remaining environmental sustainability gap(RESG) affecting the working of the environmental externality management market(EEMM), as indicated below:

3) GM.EMM $=(B C)\left(B_{M}\right)=(B B)\left(C_{M}\right)=B\left(C_{M}\right)=B(R E S G)$

Expression 3) shows that a conflict between green markets(GM) and environmental externality management market(EEMM) is a conflict between a model with no environmental sustainability gaps(ESG) and a model with remaining environmental sustainability gaps(RESG), a situation that it is summarized in Figure 4 below by placing the science based solution and the non-science based solution in the same graph:

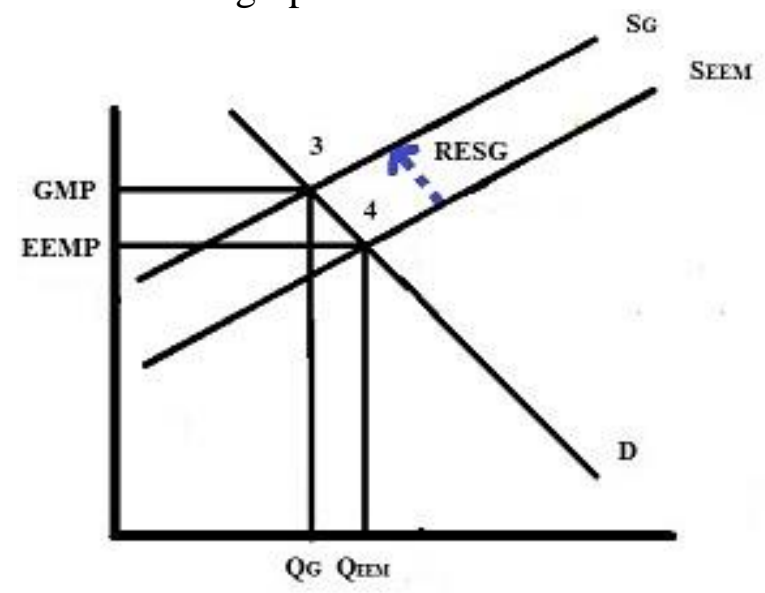

$$
\begin{aligned}
& \text { Figure } 4 \text { The clash between green markets(GM) and } \\
& \text { environmental externality management } \\
& \text { markets(EEMM) reveals the remaining environmental } \\
& \text { sustainability gap(RESG) affecting EEMM }
\end{aligned}
$$

We can appreciate in Figure 4 above the following: i) that at point 4 or arbitrary solution, there is an environmental externality management market(EEMM) with a remaining environmental sustainability gap(RESG) affecting its sustainability; and ii) that at point 3 or science based solution, there is no environmental sustainability gap(ESG). Also we can see in Figure 4 above that if the environmental cost decreases the green market price(GMP) decreases allowing for consumption and production of lower of pollution content goods and services at a lower green price such as a shift from point 3 to point 4, making pollution reduction a profitable opportunity. However, environmental externality management markets(EEMM) can only achieve lower pollution levels by increasing the environmental costs to be passed by firms to consumers and 


\section{International Journal of Business Management and Economic Review}

Vol. 3, No. 06; 2020

ISSN: 2581-4664

hence increasing the EEMP such as the shift from point 4 towards point 3, no incentive here to go the extra mile in pollution reduction.

d) The flipping of options to address the green cold war and the implications of doing this

The flipping of options summarized in Figure 4 above from a science based solution to an arbitrary solution has important implications both in terms of winner and losers in particular; and in terms of environmental sustainability in general, yet those implications are little understood as nothing as far as I know has been written about this from the sustainability angle. The discussion above raises questions such as how can the green cold war, the 2012 Rio +20 conference actions, and the fall of perfect environmentalism be linked? What are the implications of this in terms of winners and losers and of environmental sustainability? The main goal of this paper is to provide an answer to these questions using qualitative comparative means.

\section{Goals of this paper}

a) To show how the structure of the green cold war can be linked to the science and nonscience based decisions that the 2012 Rio +20 conference had available; b) To link those decisions to the proper solution of the green cold war; and c) To highlight the consequences of flipping solutions from green markets to environmental externality management markets in terms of the stakeholders involved and in terms of environmental sustainability goals.

\section{METHODOLOGY}

i) The terminology and operations concepts and rules are listed; ii) The market structure that results from resolving the green cold war in general through a science based solution under win-win situations or under no win-win situations is shared; iii) The market structure that results from resolving the green cold war in particular through a science based solution aimed at fixing the traditional market under win-win situations is provided; iv) The market structure that results from resolving the green cold war in particular through a non-science based solution aimed at patching the traditional market only under win-win is highlighted; v) The implications of flipping from science based solutions to non-science based solutions on stakeholders as winners and losers are stressed; and vi) Some food for thoughts and conclusions are provided.

\section{Terminology}

A = Active social system

$\mathrm{B}=$ Active economic system

$\mathrm{C}=$ Active environmental system

$\mathrm{S}=$ Sustainability

$\mathrm{X}=$ System $\mathrm{X}$

SSG $=$ Social sustainability gap

$\mathrm{ESG}=$ Environmental sustainability gap

$\mathrm{ENM}=$ Environmental market

$\mathrm{Q}_{\mathrm{G}}=$ Green quantity

$\mathrm{Q}_{\mathrm{T}}=$ Traditional quantity

$\mathrm{S}_{\mathrm{E}}=$ Environmental supply $\mathrm{a}=$ Passive social system

$\mathrm{b}=$ Passive economic system

$\mathrm{c}=$ Passive environmental system

$\mathrm{SG}=$ Sustainability gap

$\mathrm{Xi}=$ System $\mathrm{Xi}$

$\mathrm{ECSG}=$ Economic sustainability gap

$\mathrm{TM}=$ Traditional market

$\mathrm{GM}=$ Green market

$\mathrm{Q}_{\mathrm{E}}=$ Environmental quantity

$\mathrm{S}_{\mathrm{G}}=$ Green supply

$\mathrm{S}_{\mathrm{T}}=$ Traditional supply 
EEMM = Environmental externality management market

$\mathrm{EEM}=$ Environmental externality management

$\mathrm{S}_{\text {EEM }}=$ Environmental externality management supply

QEEM = environmental externality management quantity

EEMP $=$ Environmental externality management price

Operational concepts and paradigm merging and shift rules and expectations

i) Operational concepts

Operational concepts and externalization and internalization rules

i) Operational concepts

1) Red socialism market, the society only market.

2) Red socialism market price, the price that reflects only the social cost of production.

3) The traditional market, the economy only market.

4) The traditional market price, the general market economic only price or the price that covers the cost of production at profit $(T M P=E C M+i=P)$ or zero profit $(T M P=E C M=P)$.

5) The environmental market, the environment only market.

6) The environmental market price, the price that reflects only the environmental cost of production.

7) The socio-environmental market, the society and environment only market.

8) The socio-environmental market price, the price that reflects the social and environmental costs of production.

9) The red market, the society and economy only market.

10) The red market price, the price that reflects the social and economic costs of production.

11) The green market, the economy and environment only market.

12) The green market price, the price that reflects both the economic and the environmental cost of production or the price that covers the cost of environmentally friendly production.

13) The sustainability market, the society, economy and environment market.

14) The sustainability market price, the price that reflects the social, economic, and environmental costs of production.

15) The economic margin, to cover the economic cost of production.

16) The environmental margin, to cover the extra cost of making business environmentally friendly.

17) The social margin, to cover the extra cost of making business socially friendly.

18) Full costing, all costs are reflected in the pricing mechanism of the market.

19) Partial costing, not all costs are reflected in the pricing mechanism of the market.

20) No costing, all costs are not reflected in the pricing mechanism of the market.

21) Full responsibility, when a market uses full costing.

22) Partial responsibility, when a market uses partial costing.

23) Full irresponsibility, when a market uses no costing.

ii) Paradigm merging and shift rules and expectations

1) Paradigm merging rules(PMR) 


\section{International Journal of Business Management and Economic Review}

Vol. 3, No. 06; 2020

ISSN: 2581-4664

If "A" and "B" are dominant characteristics; and "a" and "b" are their dominated or passive counter parts, the following is expected:

a) Merging under dominant-dominant interactions

Under these conditions, dominant or active state prevails as indicated:
$(\mathrm{AA}) \rightarrow \mathrm{A}$
$(\mathrm{BB}) \rightarrow \mathrm{B}$
$(\mathrm{AA})(\mathbf{B B})=(\mathbf{A B})$
(AB) $\rightarrow$ AB

b) Merging under dominated-dominated interactions

Under these conditions, the dominated or passive form prevails as shown:
(aa) $\rightarrow$ a
(bb) $\rightarrow$ b
(aa) $(\mathbf{b b})=(\mathbf{a b})$
(ab) $\rightarrow$ ab

c) Merging under dominant-dominated interactions and win-win solutions

Under these conditions, the dominant or active system prevails as the system merge as shown below:
(Aa) $\rightarrow$ A
(bB) $\rightarrow$ B
(Aa) $(\mathbf{b B})=(\mathbf{A B})$
(ab) $\rightarrow \mathrm{AB}$

d) Merging under dominant-dominated interactions and no win-win solutions

Under these conditions, the dominated or passive system prevails and the system collapses as shown below:
(Aa) $\rightarrow$ a
(bB) $\rightarrow$ b
(Aa) $(\mathbf{b B})=(\mathrm{AB})$
(ab) $\rightarrow$ ab

2) Paradigm death expectations and shift under sustainability gaps

If we have three systems $X_{1}=B c$ and a system $X_{2}=b C$ and $X_{3}=B C$, where $c=E S G$ and $\mathrm{b}=\mathrm{ECSG}$, then the following is true:

a) Expressing models in terms of sustainability gaps

$\mathrm{X}_{1}=\mathrm{Bc}=\mathrm{B}(\mathrm{ESG}) \quad \mathrm{X}_{2}=\mathrm{bC}=(\mathrm{ECSG}) \mathrm{C}$, where $0 \leq \mathrm{ESG}<1$ and $0 \leq \mathrm{ECSG}<1$

$\mathrm{X}_{3}=\mathbf{B C}=\mathbf{B}(\mathbf{S G}=\mathbf{1}) \mathbf{C}=\mathbf{B C}$

b) Expressing inverse opposite models in conflict

$\mathbf{X}_{1} \cdot \mathbf{X}_{2}=\mathbf{B}(\mathbf{E S G}) .($ ECSG $) \mathrm{C}$

c) Paradigm death and shift expectations under no win-win conditions

When ESG ---- $\rightarrow 0$ and/or ECSG--- $\rightarrow 0$ under no win-win conditions, we have the paradigm death and shift expectation where the paradigms that die take the form of the higher level paradigm, in this case the higher level paradigm is $\mathrm{X}_{3}=\mathrm{BC}$ $X_{1} . X_{2}=B(E S G---\rightarrow 0) .(E C S G--\rightarrow 0) C=$ the death of paradigm $X_{1}, X_{2}$, or both and shift $\mathbf{X}_{1} \cdot \mathbf{X}_{2}--\rightarrow X_{3}=B C$

d) Paradigm death and shift expectations under win-win conditions

When ESG $----\rightarrow 1$ and/or ECSG---- $\rightarrow 1$ under win-win conditions, we have the paradigm shift and merger shift expectation where the paradigms that die take the form of the higher level paradigm, in this case the higher level paradigm is $\mathrm{X}_{3}=\mathrm{BC}$

$X_{1} \cdot X_{2}=B(E S G--\rightarrow 1) .(E C S G--\rightarrow 1) C=$ paradigm shift $X_{1}$ or $X_{2}$ or merger of $X_{1}$ and $X_{2}$ as

ESG $--\rightarrow 1=C$ and ECSG $--\rightarrow 1=B$ so that $X_{1} \cdot X_{2}=$

$\mathrm{B}(\mathrm{C}) .(\mathrm{B}) \mathrm{C}=\mathrm{BB} . \mathrm{CC}=\mathbf{B C}=\mathrm{X}_{\mathbf{3}}=$ merger

You can find more details about the working of paradigm death and shift expectations and merging rules in the publication Paradigm Evolution and Sustainability Thinking(Muñoz 2019). 
Vol. 3, No. 06; 2020

ISSN: 2581-4664

\section{Resolving the green cold war in general through a science based solution}

Whether under win-win situations or under no win-win situations according to the death and shift expectation rules shared in the operational concepts and rules as the green cold war reaches its end, whether individually or through merger the traditional market supply $S_{T}$ and the environmental market supply $\mathrm{S}_{\mathrm{E}}$ shift up to the left towards the green market supply $\mathrm{S}_{\mathrm{G}}$ once respected sustainability gaps are closed as indicated in Figure 5 below:

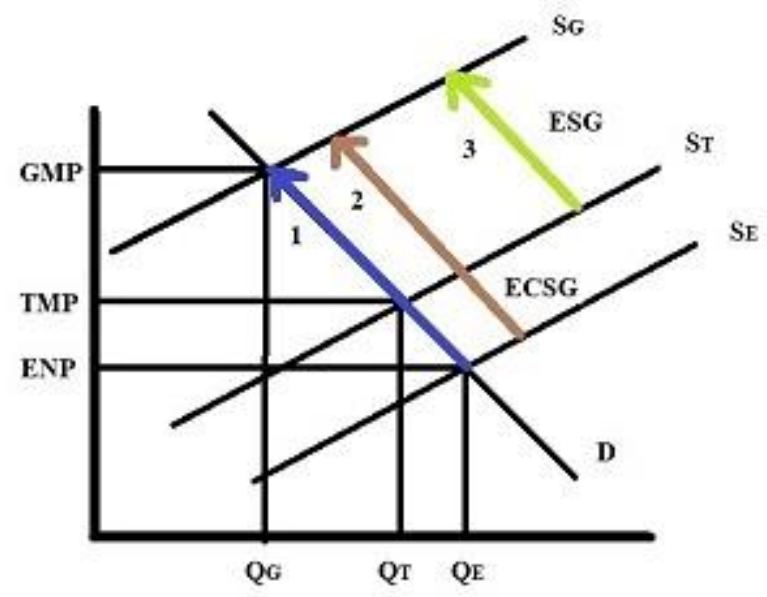

Figure 5 Resolving the greeb cold war under wib-win or under no wib-win conditions always euds with a paradigm shift to green markets(GM)

Figure 5 above help us to see that the solution to the green cold war is the green market(GM), the higher level market where the green supply $\mathrm{S}_{\mathrm{G}}$ is; and this outcome can come from the merging of the traditional market(TM) and environmental market(ENM) following the blue arrow path 1 after closing associated sustainability gaps or it can come from the fixing of the environmental market(ENM) through the closing of its economic sustainability gap(ECSG) following the brown arrow path 2 or it can come from the fixing of the traditional market(TM) through the closing of its environmental sustainability gap(ESG) following the green arrow path 3.

Hence, resolving the green cold war using science based thinking under win-win conditions or under no win-win conditions according to Figure 5 above leads to shifting merged models or individual models towards green markets(GM).

\section{The science based choice: Implementing the fixing of the traditional market model under win-win conditions}

Since the 2012 Rio +20 conference was attempting to solve the green cold war through addressing the environmental issues associated with the traditional market under win-win situations, then to move towards green markets, green growth and green economies they had to advocate for the closing of the environmental sustainability gap(ESG) affecting the sustainability of the traditional market(TM) as indicated in Figure 6 below: 
Vol. 3, No. 06; 2020

ISSN: 2581-4664

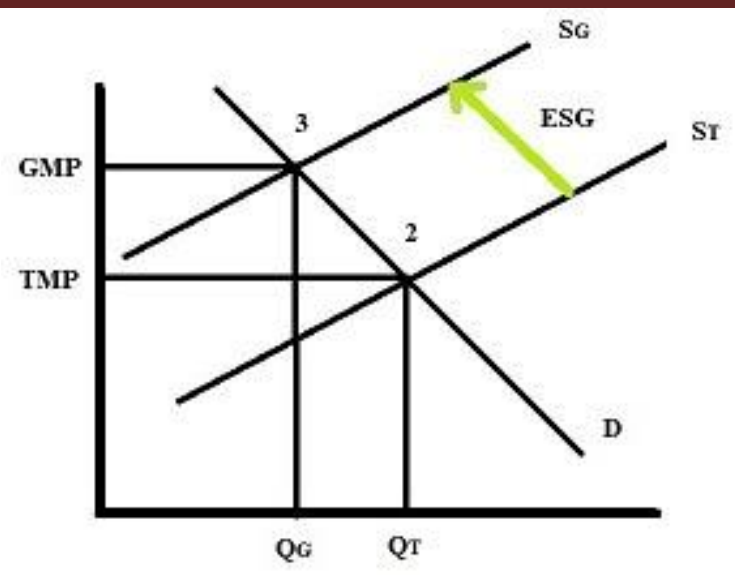

Figure 6 The shift from the traditional market(TM) to the green market(GM) when the environmental

sustainability gap(ESG) is closed under win-win conditions.

Figure 6 above tells us that closing the environmental sustainability gap(ESG) shifts the traditional market supply $S_{\mathrm{T}}$ from point 2 to point 3 and towards the green market supply $S_{\mathrm{G}}$ and the traditional market now takes the form of a green market(GM) as now the new market price, the green market price, reflects both the economic costs and environmental costs of production. And therefore, the fixing of the traditional markets through the closing its environmental sustainability gap was the science based solution to the green cold war that the 2012 Rio +20 conference had available then.

\section{The non-science based solution: the patching of the traditional market model}

The implementation of the patching of the traditional market model through the use of environmental externality management markets(EEMM) that followed the 2012 Rio +20 conference can be achieved by placing an environmental externality management supply $\mathrm{S}_{\mathrm{EEM}}$ just below the green market supply $S_{G}$, which prevents the paradigm shift from traditional market to green markets as indicated in Figure 7 below: 
Vol. 3, No. 06; 2020

ISSN: 2581-4664

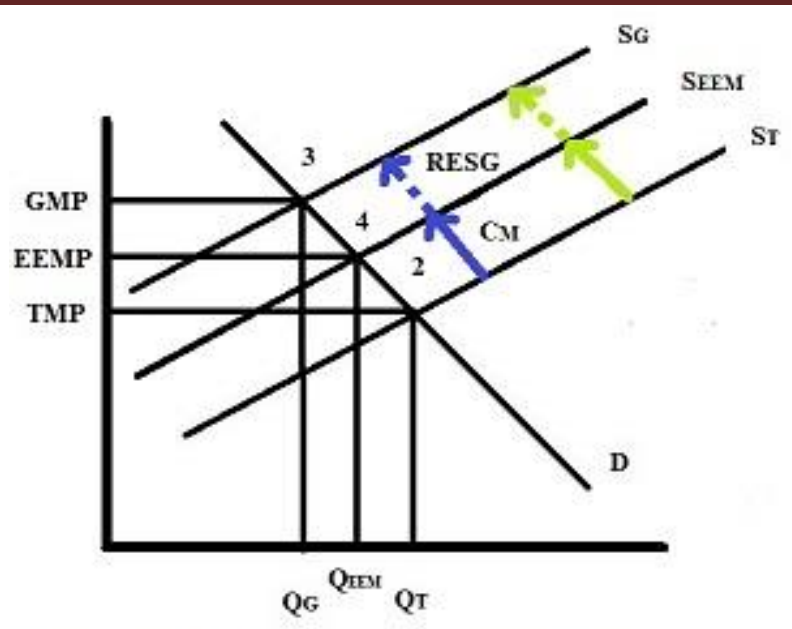

Figure 7 The structure of the patching of the traditional market(TM) through environmental externality management markets(E.MM)

We can see the following aspects in Figure 7 above: i) An environmental externality management market(EEMM) is placed at point 4 between the green market supply $S_{\mathrm{G}}$ and the traditional market supply $\mathrm{S}_{\mathrm{T}}$; and ii) that this decision leaves a remaining and active environmental sustainability gap(RESG) between point 4 and point 3 that affects the sustainability of the environmental externality management market(EEMM). We can also see in Figure 7 above that i) the environmental externality management cost $\mathrm{C}_{M}$ represented by the continuous blue arrow from point 2 to point 4 patches the portion of the environmental sustainability gap(ESG) associated with the traditional market represented by the continuous green arrow between the traditional market supply $S_{T}$ and the environmental externality management market supply $S_{\text {EEM. }}$. Therefore, consistent with Figure 7 above patching the traditional market(TM) through setting up environmental externality management markets(EEMM) is a non-science base or an arbitrary solution to the green cold war that leaves still a remaining environmental sustainability gap(RESG) still active.

Pointed out the implications of flipping from a green market solution to an environmental externality management solution to the green cold war

We can use Figure 7 above to point out who the winners and losers are when we flip a science based solution for a non-science based solution to the green cold war as indicated below:

a) The winners when going green markets

At point 3 in Figure 7 above the winners in particular are perfect market thinking and perfect environmentalism thinking as the green market reflect economic sustainability and environmental sustainability at the same time; and the winner in general is environmental sustainability as now it is an endogenous issue to the green market model, not an exogenous issue as it was under traditional market thinking. At point 3 in Figure 7 above, imperfect traditional market thinking and imperfect environmental thinking do not work as they are inconsistent with the structure of green markets.

b) The winners when going environmental externality management market 


\section{International Journal of Business Management and Economic Review}

Vol. 3, No. 06; 2020

ISSN: 2581-4664

At point 4 in Figure 7 above the winners in particular are imperfect market thinking and imperfect environmentalism thinking as the environmental externality management market reflects economic sustainability and environmental externality management at the same time under non-free market conditions; and the winner in general is environmental externality management as now it is an endogenous issue to the traditional market model. At point 4 in Figure 7 above, perfect traditional market thinking and perfect environmental thinking do not work as they are inconsistent with the structure of environmental externality management markets.

\section{c) The losers when we flip from green markets to environmental externality management} market as the solution to the green cold war

When we flip solutions to the green cold war from point 3 to point 4 in Figure 7 above the losers in particular are perfect market thinking and perfect environmentalism thinking as environmental externality management markets are imperfect markets that do not require economic sustainability and environmental sustainability at the same time to exist; and the loser in general as now environmental management is an endogenous issue to the model, not environmental sustainability. Hence, at point 4 in Figure 7 above, imperfect traditional market thinking and imperfect environmental thinking works under ongoing remaining environmental sustainability gap pressures.

\section{Implications:}

In both cases, science based solutions and non-science based solutions discussed above, economic sustainability is always a winner as economic sustainability can exist under perfect market thinking(e.g. green markets) and imperfect market thinking(e.g. environmental externality management markets). While environmental sustainability can only be a winner when under perfect green markets; and it will always be a loser under environmental externality management markets.

\section{Food for thoughts}

i) Can we solve an environmental problem without fixing it? I think no, what do you think?; ii) Can the remaining environmental sustainability gap lead to the fall of the environmental externality management markets in the future? I think yes, what do you think?; and iii) Can environmental externality management markets exist without permanent external intervention? I think no, what do you think?

\section{CONCLUSIONS}

1) It was shown that a green cold war is resolved using science based thinking under winwin conditions or under no win-win conditions by shifting merged models or individual models towards green markets; 2) It was stressed that the fixing of the traditional markets after closing its environmental sustainability gap was the science based solution the 2012 Rio +20 conference had; 3) It was pointed out that patching the traditional market through setting up environmental externality management markets is a non-science base or an arbitrary solution that leaves still a remaining environmental sustainability gap still active; 4) It was highlighted that when shifting to green markets is the solution, then perfect market thinking and perfect environmentalism thinking are the winners as well as sustainability as a whole as both economic and environmental sustainability are required at the same time; 5) It was indicated that when using environmental 


\section{International Journal of Business Management and Economic Review}

Vol. 3, No. 06; 2020

ISSN: 2581-4664

externality management markets is the way to go, perfect market thinking and perfect environmentalism thinking as well as environmental sustainability are the losers as these markets do not require environmental sustainability and perfect free market thinking to exist.

\section{REFERENCES}

Carson, Rachel, 1962. Silent Spring II, A reporter at large, June 23, The New Yorker Magazine, New York, NY, USA.

Mackie, John, 2017. Canada 150: The couples that founded Greenpeace, June 02, The Vancouver Sun, Vancouver, BC, Canada.

Muñoz, Lucio, 2016a. Beyond Traditional Market Thinking: What is the Structure of the Perfect Green market?, In: International Journal of Science Social Studies Humanities and Management (IJSSSHM), Vol. 2, No. 5., May, Ed. Dr. Maya Pant, India.

Muñoz, Lucio, 2016b. Perfect Green Markets vrs Dwarf Green Markets: Did We Start Trying to Solve the Environmental Crisis in 2012 With the Wrong Green Foot? If Yes, How Can This Situation Be Corrected?. In: International Journal of Advanced Engineering and Management Research(IJAEMR), Vol.1, Issue 6, Pp 389-406, August, India.

Muñoz Lucio, 2019. Paradigm Evolution and Sustainability Thinking: Using a Sustainability Inversegram to State Paradigm Death and Shift Expectations Under WinWin and No Win-Win Situations. In: Current Perspective to Economics and Management, Vol. 1, Chapter 2, June 12, Book Publisher International, London, UK.

Muñoz, Lucio, 2020. Sustainability thoughts 119: How can the 2012 green cold war be stated graphically in terms of sustainability gaps? What are the implications of this in terms of the only possible science based resolution to the green cold war?, In: International Journal of Management studies and Social Science Research(IJMSSSR), Vol. 2, Issue 5, September-October, Pp 128-137, ISSN: 2582-0265, India.

United Nations(UN), 1992. United Nations Conference on Environment \& Development Rio de Janerio, Brazil, 3 to 14 June 1992, AGENDA 21, Sustainable Development, New York, NY, USA.

United Nations Conference on Sustainable Development(UNCSD), 2012a. Rio+20 Concludes with Big Package of Commitments for Action and Agreement by World Leaders on Path for a Sustainable Future, Press Release, June 20-22, New York, NY, USA.

United Nations Conference on Sustainable Development(UNCSD), 2012b. The Future We Want, June 20-22, New York, NY, USA.

World Commission on Environment and Development(WCED), 1987. Our Common Future, Oxford University Press, London, UK. 